\title{
Decreased B Lymphocytes Subpopulations Are Associated With Higher Atherosclerotic Risk in Elderly Patients With Moderate-to-severe Chronic Kidney Diseases
}

Jieshan Lin

Guangdong Academy of Medical Sciences, Guangdong Provincial Geriatrics Institute

Bin Tang

Zhongshan People's Hospital

Zhanwu Feng

Guangdong Academy of Medical Sciences

Wenke Hao

Guangdong Academy of Medical Sciences, Guangdong Provincial Geriatrics Institute

Wenxue Hu ( $\nabla$ wuleihu@126.com )

Guangdong Academy of Medical Sciences, Guangdong Provincial Geriatrics Institute

\section{Research Article}

Keywords: B cells, Atherosclerosis, Intima-media thickness, Elderly, Chronic kidney disease

Posted Date: September 1st, 2021

DOI: https://doi.org/10.21203/rs.3.rs-695618/v1

License: (c) (i) This work is licensed under a Creative Commons Attribution 4.0 International License.

Read Full License

Version of Record: A version of this preprint was published at BMC Nephrology on November 30th, 2021. See the published version at https://doi.org/10.1186/s12882-021-02613-6. 


\section{Abstract}

Aim: Cardiovascular diseases (CVD) are the leading cause of death in patients with chronic kidney disease (CKD), and the risk of CVD increases with reductions in renal function. This study aims to investigate the potential roles of $B$ lymphocyte populations in subclinical atherosclerosis (measured by intima-media thickness, IMT) and prognosis in elderly patients with moderate-to-severe CKD.

Methods: In this study, a total of 219 patients (143 moderate-to-severe CKD patients with stage 3-4 and 76 non-CKD controls) were recruited. B cell subsets: B1 cells (CD19+CD5+) and B2 cells (CD19+CD5-) were analyzed by flow cytometry. Intima-media thickness (IMT) was measured by ultrasound. Correlations between the B cell subsets with IMT and clinical outcomes were analyzed.

Results: CKD patients showed increased IMT $(P=0.006)$. The level of $B, B 1$ and $B 2$ cells were decreased in CKD patients. Correlation analysis showed that IMT was positively correlated with systolic blood pressure, protein/creatinine ratio and diabetes $(P<0.05)$, and were negatively correlated with $B, B 1$ and $B 2$ lymphocytes $(P<0.05)$. IMT was increased in lower level of $B\left(\leq 0.06 \times 10^{9} / L\right)$ and $B 2$ cells $\left(\leq 0.05 \times 10^{9}\right.$ /L) $(P<0.05)$. Kaplan-Meier analysis showed that patients with lower level of $B, B 1$ and $B 2$ cells exhibited worse survival $(P<0.05)$.

Conclusions: Our results showed that decreased B1 and B2 lymphocytes were correlated with atherosclerosis and worse survival, which indicates that B lymphocytes might involve in atherosclerosis and associated the prognosis of elderly patients with moderate-to-severe CKD.

\section{Introduction}

Cardiovascular diseases (CVD) are the leading cause of death in patients with chronic kidney disease (CKD), and the risk of CVD increases with reductions in renal function[1]. It is well known that CKD on hemodialysis is closely associated with accelerated atherosclerosis. However, recent studies have shown that increased atherosclerosis risk was actually observed in the early stages of CKD and remains stable thereafter[2]. Atherosclerosis is intimately interconnected with the immune system and recently, the influence of immune abnormalities on the pathogenesis of atherosclerosis and the possible discovery of new treatment methods have been increasingly studied[3]. Several studies have indicated that $T$ cells promote atherosclerosis, whereas $B$ cells may have a protective role $[4,5]$.

B cells can broadly be divided 2 subsets: innate B1 cells (CD19 + CD5+) and conventional B2 (CD19+ CD5-) cells[5]. B1 cells are largely fetal liver derived and considered to be elements of the innate immune system. They patrol mucosal surfaces, provide immediate defense and antigen capture, as well as modulate and systematically transport invading bacteria. B1 cells may have a protective effect on atherosclerosis that is largely mediated by the production of IgM antibodies. And these antibodies constitute a readily available pool of immunoglobulins for use against a variety of infections before specific high-affinity antibodies are produced[6]. B2 cells are bone marrow derived and differentiate into 
plasma cells and produce high affinity, class-switched antibodies in a T cell dependent manner that are responsible for developing an adaptive response[7].

Studies have suggested B cells may play the protective effect on atherosclerosis. Clinical studies have also reported a negative association between (IgM-producing) memory B cells and risk of CVD[8, 9]. In addition, distinct knockout mouse models targeting $B$ cell subsets differentially have revealed the antiatherogenic potentials of B1 and B2 cells[10-12]. Our previous data and some other results showed that $\mathrm{B} 1$ and $\mathrm{B} 2$ cells exhibited a significantly negative correlation with the progression of CKD in elderly patients and patients with lower decreased B cell counts had a higher risk of CVD mortality[13, 14]. However, the roles of B cell subpopulations in atherosclerosis of elderly patients with CKD are unclear.

Ultrasonic measurement of the thickness of the carotid intima-media thickness (IMT) is a noninvasive and reliable tool to assess asymptomatic atherosclerosis and increased IMT is an independent predictor of future cardiovascular risk[15]. IMT is increased in CKD patients and may help to predict patients at higher risk of future CVD[16]. Therefore, the aim of this study was to investigate the potential roles of peripheral blood B lymphocyte populations in subclinical atherosclerosis (measured by IMT) and prognosis in elderly patients with moderate-to-severe CKD.

\section{Materials And Methods}

\section{Patients}

A total of 143 patients with moderate-to-severe CKD (stage 3-4) aged $\geq 65$ years were retrospectively studied in Guangdong Provincial People's Hospital from January 2010 to December 2018. CKD is defined as abnormalities of kidney structure or function, present for $>3$ months. The criteria for CKD are as follows: (1) decreased GFR (for $>3$ months): GFR $<60 \mathrm{ml} / \mathrm{min} / 1.73 \mathrm{~m}^{2}$, and/ or (2) markers of kidney damage ( $>1$ for $>3$ months): albuminuria, electrolyte, urinary sediment abnormalities, and other abnormalities due to abnormalities detected by histology, tubular disorders, structural abnormalities detected by imaging, history of kidney transplantation. The estimated glomerular filtration rate (eGFR) was calculated using CKD-EPI equation, and the definition of stage 3 was eGFR from 30 to 59 $\mathrm{ml} / \mathrm{min} / 1.73 \mathrm{~m}^{2}$, stage 4 was eGFR from 15 to $29 \mathrm{ml} / \mathrm{min} / 1.73 \mathrm{~m}^{2}$. Patients with acute kidney injury, malignancy, active infection, thyroid malfunction, heart failure or on immunosuppressive drugs were excluded.

The control group (76 patients) without CKD included patients hospitalized for hypertension, prostatic hyperplasia and osteoporosis. For all patients, we recorded clinical data, including age and sex, serum creatinine (SCr), protein/creatinine ratio, serum albumin (ALB), cholesterol, triglyceride, white blood cell (WBC), lymphocytes and neutrophil levels; and comorbidities such as diabetes and hypertension. SCr was measured by the enzymatic method. The study involving human participants was approved by the Ethical Committee of Guangdong Provincial People's Hospital.

\section{Clinical Outcomes}


Outcomes of this study were all-cause mortality. All patients were followed until the date of their last visit, and the median follow-up duration was 41.5 months.

\section{Estimation of Intima-media Thickness}

The IMT was measured bilaterally at the far wall over the distal $1.5-\mathrm{cm}$ segment of the common carotid artery by using a high-resolution 4- to 13-MHz linear-array transducer system. For each subject, the mean IMT was computed as the average IMT on both sides.

\section{Flow Cytometry Analysis (FCM)}

Peripheral blood lymphocyte populations (CD3+ T lymphocytes, CD19+ B lymphocytes, CD19+CD5+ B1 lymphocytes, and CD19+CD5- B2 lymphocytes) were analyzed by flow cytometry. Blood samples obtained by venipuncture were collected in EDTA anticoagulant. $10 \mu$ of anti-human CD3-PerCP, CD19APC, and CD5-PE antibodies were added to $100 \mu \mathrm{l}$ of whole blood and incubated for $20 \mathrm{~min}$ at $4 \circ \mathrm{C}$ in the dark. A total of $2 \mathrm{ml}$ of red blood cell lysis buffer was added before staining to each tube, vortexed well, and incubated for $10 \mathrm{~min}$ at room temperature in darkness. Then, the cells were washed twice with phosphate buffer saline (PBS), and then discarded the supernatant. Last, 20,000 cells were acquired by using FACS (BD USA) and were analyzed using Cellquest-Pro analysis software to determine the subpopulation counts (Figure 1).

\section{Statistical Analysis}

Data are expressed as mean \pm SEM. Statistical analyses were performed using SPSS version 20.0 (Chicago, IL, USA). Continuous variables were analyzed by the Wilcoxon rank-sum test. The correlations between IMT and clinical data were performed using the Spearman's test. The X-tile software version 3.6.1 (Yale University, New Haven, USA) was used to determine the optimal cutoff points of IMT and different B cells based on the outcome. The optimal cutoff points of IMT, B cells, B1 cells and B2 cells were $1.0 \mathrm{~cm}, 0.06 \times 10^{9} / \mathrm{L}, 0.03 \times 10^{9} / \mathrm{L}$ and $0.05 \times 10^{9} / \mathrm{L}$, respectively. The Kaplan-Meier survival analysis method with the log-rank test was used to compare survival times. All $p$ values were calculated two-sided and a value of $<0.05$ was considered significant.

\section{Results}

\section{Patient and Demographic Details}

The clinical and demographic data of the study subjects are shown in tables 1 . There were 219 patients entered in the final analysis: 76 control subjects and 143 patients with CKD stage 3-4. The majority of patients were males. $86.01 \%$ of the CKD patients had hypertension and $42.66 \%$ were with diabetic.

\section{Intima-media Thickness and B Cell Subpopulations}


The common carotid artery IMT was $1.01 \pm 0.17 \mathrm{~cm}$ in CKD patients and $0.94 \pm 0.16 \mathrm{~cm}$ in the control group $(P=0.006)$. Comparison of $B 1$ cells in the two groups revealed remarkable differences, and the number of $B$ lymphocyte subpopulation was decreased in CKD patients. The average levels of $B, B 1$ and B2 lymphocytes in CKD patients were $(0.15 \pm 0.11) \times 10^{9} / \mathrm{L},(0.05 \pm 0.07) \times 10^{9} / \mathrm{L}$ and $(0.10 \pm 0.06) \times 10^{9} / \mathrm{L}$, respectively, while in the control group were $(0.22 \pm 0.36) \times 10^{9} / L(P=0.059),(0.10 \pm 0.33) \times 10^{9} / L(P=0.004)$ and $(0.12 \pm 0.09) \times 10^{9} / \mathrm{L}(\mathrm{P}=0.088)$, respectively (Table 1$)$.

\section{The Correlation Between IMT and Clinical Data}

Spearman's analysis showed that IMT was positively correlated with systolic blood pressure $(R=0.282$, $P=0.001)$, protein/creatinine ratio $(R=0.253, P=0.016)$ and diabetes $(R=0.267, P=0.001)$. However, age, diastolic blood pressure, the level of $\mathrm{SCr}$, cholesterol, triglyceride, WBC counts and neutrophil were not associated with IMT. We further analyzed association of IMT and B cells, B1 cells and B2 cells. Our data revealed that IMT was negatively correlated with $B$ lymphocytes $(R=-0.209, P=0.012), B 1$ lymphocytes $(R=-0.195, P=0.020)$ and $B 2$ lymphocytes $(R=-0.208, P=0.013)$. In contrast, in the control group, only diabetes $(R=0.243, P=0.034)$ exhibited positive correlation with IMT (Table 2).

\section{Comparison of IMT between low and high level of different B cells in the total cohort and CKD group}

We used X-tile software to determine the optimal cutoff points of B, B1 and B2 cells based on the outcome. And the cutoff points for the grouping of $B, B 1$, and B2 cells were $0.06 \times 10^{9} / L, 0.03 \times 10^{9} / \mathrm{L}$ and $0.05 \times 10^{9} / \mathrm{L}$, respectively. As shown in Figure 2, IMT was increased in the lower level of $B$ and B2 cells. IMT was increased in $B$ cells $\leq 0.06 \times 10^{9} / L$ in the total cohort $(1.06 \pm 0.18$ vs. $0.97 \pm 0.16, P=0.004)$ and CKD group ( $1.11 \pm 0.18$ vs. $0.99 \pm 0.16, P=0.003)$. Similarly, IMT was also increased in $B 2$ cells $\leq 0.05 \times$ $10^{9} / \mathrm{L}$ in the total cohort $(1.05 \pm 0.18$ vs. $0.97 \pm 0.16, P=0.006)$ and CKD group $(1.08 \pm 0.19$ vs. $0.99 \pm 0.16$, $\mathrm{P}=0.004)$. Though IMT was increased in $\mathrm{B} 1$ cells $\leq 0.03 \times 10^{9} / \mathrm{L}$, the difference was not significant $(P>0.05)$.

\section{Association of IMT and different B cells with overall survival}

As mentioned above, patients were divided into two groups according to the optimal cutoff points, and the cutoff point of IMT was $1.0 \mathrm{~cm}$. Kaplan-Meier analysis showed that patients with IMT $\leq 1.0$ $\mathrm{cm}$ present longer survival in the total cohort $(83.92 \pm 4.03$ vs. $73.99 \pm 4.48$ months, $P=0.075$, Figure $3 \mathrm{~A})$ and CKD group (75.64 \pm 5.83 vs. $63.35 \pm 4.60, P=0.156$ months, Figure $3 B$ ), but the difference was not statistically significant. Patients with $B$ cells $>0.06 \times 10^{9} / \mathrm{L}$ showed prolonged survival in the total cohort (50.07 \pm 4.53 vs. $83.51 \pm 3.23$ months, $P=0.001$, Figure $3 C$ ) and CKD group ( $45.35 \pm 6.27$ vs. $73.29 \pm 4.12$, $\mathrm{P}=0.006$ months, Figure $3 \mathrm{D}$ ). The group with $\mathrm{B} 1$ cells $>0.03 \times 10^{9} / \mathrm{L}$ also had better survival in the total cohort ( $67.27 \pm 4.55$ vs. $89.11 \pm 3.65$ months, $P=0.001$, Figure $3 E$ ) and CKD group ( $57.83 \pm 5.35$ vs. $81.43 \pm 4.80$ months, $P=0.002$, Figure $3 F$ ). The results of $B 2$ cells were similar, higher levels of $B 2$ cells $\left(>0.05 \times 10^{9} / \mathrm{L}\right)$ exhibited better survival in the total cohort $(57.57 \pm 7.16$ vs. $83.86 \pm 3.26$ months, $P=0.001$, Figure $3 G)$ and CKD group (49.18 \pm 7.98 vs. $73.73 \pm 4.16$ months, $P=0.007$, Figure $3 \mathrm{H}$ ). 


\section{Discussion}

In CKD subjects, cardiovascular disease is a major cause of their morbidity and mortality, account for $40 \%$ of deaths among patients with end-stage renal disease (ESRD)[17]. CKD accelerates atherosclerosis via augmentation of inflammation, perturbation of lipid metabolism, and other mechanisms[4]. It has been well established that the innate and adaptive immunity contribute to the development of atherosclerosis, and B cells have emerged as important modulators of inflammatory effects in atherosclerosis[5]. B lymphocytes are generated from hematopoietic stem cells in bone marrow. Murine $B$ cells are broadly divided into B1 and B2 subsets, B1 cells secrete $\lg \mathrm{M}$ and $\lg \mathrm{A}$ while $\mathrm{B} 2$ cells that produce $\lg \mathrm{G}[6]$. Previous studies have shown that B lymphocytes have a protective effect on atherosclerosis[1012]. However, few studies have analyzed the relationship between $B$ cell subsets and atherosclerosis of moderate-to-severe CKD patients in the elderly.

In this study, we found that IMT was positively correlated with systolic blood pressure, protein/creatinine ratio and diabetes. Hypertension is a major risk factor for the development of atherosclerosis. In hypertension, changes in microcirculation can cause endothelial dysfunction, then promotes the formation of atherosclerotic plaque[18]. Atherosclerosis is the most important cause of morbidity and mortality in CKD. And Sumida et al[19] showed that carotid artery calcification was significantly associated with proteinuria in ESRD patients. Diabetic macroangiopathy, atherosclerosis secondary to diabetes, is characterized by the alterations in vascular homeostasis due to endothelial and vascular smooth muscle cell dysfunction[20].

In addition, our results showed that B lymphocytes, B1 lymphocytes and B2 lymphocytes were negatively correlated IMT. B cells are divided into B1 and B2 subsets. B1 cells have been reported to protect from atherosclerosis by the production of $\operatorname{lgM}$ antibodies. IgM antibodies have the capacity to recognize apoptotic cells and Oxidized LDL (OxLDL) and limit foam cell formation and OxLDL-induced endothelial activation[5]. Gruber et al[12] studied the Siglec-G-deficient mice and found that B-1 cell-derived natural IgM had an effect on decreasing levels of OxLDL and oxidation-specific epitopes, so could reduce atherosclerosis. In addition, previous studies have also showed that B1 cells were significant source of interleukin 10 (IL10), which also exert atheroprotection[21]. Our results showed that the level of B1 cells was significantly decreased in moderate-to-severe CKD patients and IMT was increased in the lower level of B1 cells, that could explain why patients with CKD exhibit accelerated development of atherosclerosis.

Moreover, our data also showed that B2 lymphocytes were negatively correlated IMT and IMT was significantly increased in the lower level of B2 cells. Genomic data showed that the survival of B2 lymphocytes was mainly dependent on the B cell-activating factor (BAFF) receptor pathway[22]. Tsiantoulas et al [23] studied Apoe-/- and Ldlr-/- mice and found that anti-BAFF antibody treatment could deplete B2 lymphocytes and increased atherosclerosis. In CKD patients, the uremic environment may promote resistance to BAAF-mediated signals and interfere the maturation of transitional $\mathrm{B}$ cells to mature B cells[24]. Therefore, decreased B2 Lymphocytes might be associated with the uremic environment and was correlated with atherosclerosis. 
Furthermore, our study showed that IMT was increased in lower level of B, B1 and B2 cells, and moderateto-severe CKD patients with lower level of B, B1 and B2 cells exhibited worse survival. Progressive loss of renal function is associated with immune deficiency, and account for the large proportion of morbidity and mortality[25]. Molina et al.[13] showed that patients with lower level of B cells had a higher risk of CVD and all-cause mortality. These data indicated that higher level of B cells may play a protective role in CKD and had a potential effect of inhibiting atherosclerosis.

However, our study also had certain limitations. Firstly, this was a retrospective study. Secondly, we did not explore the mechanisms of different B lymphocytes in atherosclerosis. Further studies should be carried out to explore these results.

In conclusion, our results showed that decreased B1 and B2 lymphocytes were correlated with atherosclerosis and worse clinical outcomes $₫$ which indicated that $B$ lymphocytes may be involved in pathogenesis of atherosclerosis and associated with prognosis in moderate-to-severe CKD.

\section{Abbreviations}

Cardiovascular diseases: CVD

Chronic kidney disease: CKD

Intima-media thickness: IMT

Estimated glomerular filtration rate: eGFR

Serum creatinine: $\mathrm{SCr}$

Serum albumin: ALB

White blood cell: WBC

Phosphate buffer saline: PBS

End-stage renal disease: ESRD

Oxidized LDL: OxLDL

Interleukin 10: IL10

B cell-activating factor: BAFF

\section{Declarations}

\section{Acknowledgements}


Not applicable.

\section{Funding}

No funding was obtained for this study.

\section{Ethics approval and consent to participate}

The studies involving human participants were reviewed and approved by the Ethical Committee of Guangdong Provincial People's Hospital. The patients/participants provided their written informed consent to participate in this study.

\section{Consent for publication}

Not applicable.

\section{Conflict of interest}

The authors declare that they have no competing interests.

\section{Availability of data and material}

The datasets are available from the corresponding author on reasonable request.

\section{Author contributions}

Jieshan Lin was involved in study design, interpreting data, statistical analysis, creating tables and figures, and writing of the manuscript. Bin Tang and Wenke Hao were involved in data interpretation and statistical analysis. Zhanwu Feng took part in ultrasound analysis. Wenxue Hu designed the research and supervised the work. All authors have read and approved the manuscript.

\section{References}

1. Schiffrin EL, Lipman ML, Mann JF. Chronic kidney disease: effects on the cardiovascular system. Circulation 2007;116:85-97.

2. Valdivielso JM, Rodríguez-Puyol D, Pascual J, et al. Atherosclerosis in Chronic Kidney Disease: More, Less, or Just Different? Arterioscler Thromb Vasc Biol 2019;39:1938-1966.

3. Frostegård J. Immunity, atherosclerosis and cardiovascular disease. BMC Med 2013;11:117.

4. Gisterå A, Hansson GK. The immunology of atherosclerosis. Nat Rev Nephrol 2017;13:368-380.

5. Upadhye A, Sturek JM, McNamara CA. 2019 Russell Ross Memorial Lecture in Vascular Biology: B Lymphocyte-Mediated Protective Immunity in Atherosclerosis. Arterioscler Thromb Vasc Biol 2020;40:309-322. 
6. Choi YS, Dieter JA, Rothaeusler K, et al. B-1 cells in the bone marrow are a significant source of natural IgM. Eur J Immunol 2012;42:120-129.

7. Gil-Borras R, García-Ballesteros C, Benet-Campos C, et al. B1a Lymphocytes (CD19 + CD5+) Deficiency in Patients with Crohn's Disease and Its Relation with Disease Severity. Dig Dis 2018;36:194-201.

8. Mantani PT, Ljungcrantz I, Andersson L, et al. Circulating CD40 + and CD86 + B cell subsets demonstrate opposing associations with risk of stroke. Arterioscler Thromb Vasc Biol 2014;34:211218.

9. Meeuwsen JAL, van Duijvenvoorde A, Gohar A, et al. High Levels of (Un)Switched Memory B Cells Are Associated With Better Outcome in Patients With Advanced Atherosclerotic Disease. J Am Heart Assoc 2017;6.

10. Kyaw T, Tay C, Krishnamurthi S, et al. B1 a B lymphocytes are atheroprotective by secreting natural $\operatorname{IgM}$ that increases IgM deposits and reduces necrotic cores in atherosclerotic lesions. Circ Res 2011;109:830-840.

11. Doran AC, Lipinski MJ, Oldham SN, et al. B-cell aortic homing and atheroprotection depend on Id3. Circ Res 2012;110:e1-12.

12. Gruber S, Hendrikx T, Tsiantoulas D, et al. Sialic Acid-Binding Immunoglobulin-like Lectin G Promotes Atherosclerosis and Liver Inflammation by Suppressing the Protective Functions of B-1 Cells. Cell Rep 2016;14:2348-2361.

13. Molina M, Allende LM, Ramos LE, et al. CD19(+) B-Cells, a New Biomarker of Mortality in Hemodialysis Patients. Front Immunol 2018;9:1221.

14. Lin J, Tang W, Liu W, et al. Decreased B1 and B2 Lymphocytes Are Associated With Mortality in Elderly Patients With Chronic Kidney Diseases. Front Med (Lausanne) 2020;7:75.

15. Gepner AD, Wyman RA, Korcarz CE, et al. An abbreviated carotid intima-media thickness scanning protocol to facilitate clinical screening for subclinical atherosclerosis. J Am Soc Echocardiogr 2007;20:1269-1275.

16. Hinderliter A, Padilla RL, Gillespie BW, et al. Association of carotid intima-media thickness with cardiovascular risk factors and patient outcomes in advanced chronic kidney disease: the RRI-CKD study. Clin Nephrol 2015;84:10-20.

17. Hakeem A, Bhatti S, Chang SM. Screening and risk stratification of coronary artery disease in endstage renal disease. JACC Cardiovasc Imaging 2014;7:715-728.

18. Petrie JR, Guzik TJ, Touyz RM. Diabetes, Hypertension, and Cardiovascular Disease: Clinical Insights and Vascular Mechanisms. Can J Cardiol 2018;34:575-584.

19. Sumida $Y$, Nakayama M, Nagata $M$, et al. Carotid artery calcification and atherosclerosis at the initiation of hemodialysis in patients with end-stage renal disease. Clin Nephrol 2010;73:360-369.

20. Katakami N. Mechanism of Development of Atherosclerosis and Cardiovascular Disease in Diabetes Mellitus. J Atheroscler Thromb 2018;25:27-39. 
21. Lu H, Daugherty A. Regulatory B cells, interleukin-10, and atherosclerosis. Curr Opin Lipidol 2015;26:470-471.

22. Sage AP, Tsiantoulas $D$, Baker $L$, et al. BAFF receptor deficiency reduces the development of atherosclerosis in mice-brief report. Arterioscler Thromb Vasc Biol 2012;32:1573-1576.

23. Tsiantoulas D, Sage AP, Göderle L, et al. B Cell-Activating Factor Neutralization Aggravates Atherosclerosis. Circulation 2018;138:2263-2273.

24. Vaziri ND, Pahl MV, Crum A, et al. Effect of uremia on structure and function of immune system. J Ren Nutr 2012;22:149-156.

25. Kim KW, Chung BH, Jeon EJ, et al. B cell-associated immune profiles in patients with end-stage renal disease (ESRD). Exp Mol Med 2012;44:465-472.

\section{Tables}


Table 1. Clinical characteristics and laboratory parameters of older patients with or without CKD.

\begin{tabular}{|c|c|c|c|}
\hline & Control subjects & CKD patients & $P$ value \\
\hline Number of cases & 76 & 143 & \\
\hline Age, years & $80.32 \pm 4.34$ & $82.70 \pm 4.89$ & $<0.001^{*}$ \\
\hline Gender (M/F) & $60 / 16$ & $115 / 28$ & $<0.001^{*}$ \\
\hline Hypertension & $60.53 \%$ & $86.01 \%$ & $<0.001^{\star}$ \\
\hline Systolic blood pressure, $\mathrm{mmHg}$ & $134.37 \pm 16.78$ & $143.66 \pm 16.62$ & $<0.001^{*}$ \\
\hline Diastolic blood pressure, $\mathrm{mmHg}$ & $71.17 \pm 9.09$ & $74.66 \pm 10.22$ & $0.005^{*}$ \\
\hline Diabetes & $23.68 \%$ & $42.66 \%$ & $0.005^{\star}$ \\
\hline $\mathrm{SCr}(\mu \mathrm{mol} / \mathrm{L})$ & $77.64 \pm 11.47$ & $145.55 \pm 50.42$ & $<0.001^{*}$ \\
\hline eGFR CKD-EPI (ml/min/1.73 m²) & $78.32 \pm 10.65$ & $40.98 \pm 13.49$ & $<0.001^{*}$ \\
\hline Albumin $(\mathrm{g} / \mathrm{L})$ & $35.00 \pm 33.72$ & $33.72 \pm 4.97$ & 0.075 \\
\hline protein/creatinine ratio $(\mathrm{mg} / \mathrm{g} \mathrm{Cr})$ & $115.17 \pm 98.40$ & $776.87 \pm 1587.69$ & $<0.001^{*}$ \\
\hline Cholesterol (mmol/L) & $4.19 \pm 0.90$ & $4.43 \pm 1.29$ & 0.401 \\
\hline Triglyceride (mmol/L) & $1.12 \pm 0.60$ & $1.36 \pm 0.89$ & $0.040^{*}$ \\
\hline IMT囚cm) & $0.94 \pm 0.16$ & $1.01 \pm 0.17$ & $0.006^{*}$ \\
\hline WBC $\left(10^{9} / \mathrm{L}\right)$ & $6.17 \pm 1.95$ & $6.43 \pm 1.92$ & 0.247 \\
\hline Neutrophil $\left(10^{9} / \mathrm{L}\right)$ & $3.75 \pm 1.51$ & $4.20 \pm 1.59$ & $0.027^{*}$ \\
\hline T lymphocytes $\left(10^{9} / \mathrm{L}\right)$ & $1.09 \pm 0.44$ & $0.33 \pm 0.21$ & 0.175 \\
\hline B lymphocytes $\left(10^{9} / \mathrm{L}\right)$ & $0.22 \pm 0.36$ & $0.15 \pm 0.11$ & 0.059 \\
\hline B1 lymphocytes $\left(10^{9} / \mathrm{L}\right)$ & $0.10 \pm 0.33$ & $0.05 \pm 0.07$ & $0.040^{*}$ \\
\hline B2 lymphocytes $\left(10^{9} / \mathrm{L}\right)$ & $0.12 \pm 0.09$ & $0.10 \pm 0.06$ & 0.088 \\
\hline
\end{tabular}

eGFR, estimated glomerular filtration rate; SCr, serum creatinine; IMT, intima-media thickness; WBC, white blood cell. 
Table 2. Correlation between IMT with the clinical data of older patients with or without CKD.

\begin{tabular}{|c|c|c|}
\hline Variable & IMT (Control) & IMT (CKD) \\
\hline \multirow[t]{2}{*}{ Age } & $R=-0.071$ & $R=0.147$ \\
\hline & $P=0.545$ & $P=0.08$ \\
\hline \multirow[t]{2}{*}{ Systolic blood pressure } & $R=0.063$ & $R=0.282$ \\
\hline & $P=0.589$ & $P=0.001^{*}$ \\
\hline \multirow[t]{2}{*}{ Diastolic blood pressure } & $R=-0.102$ & $R=-0.022$ \\
\hline & $P=0.381$ & $P=0.792$ \\
\hline \multirow[t]{2}{*}{ Diabetes } & $R=0.243$ & $R=0.267$ \\
\hline & $P=0.034^{*}$ & $P=0.001^{*}$ \\
\hline \multirow[t]{2}{*}{$\mathrm{SCr}$} & $R=0.013$ & $R=0.036$ \\
\hline & $P=0.914$ & $P=0.671$ \\
\hline \multirow[t]{2}{*}{ Protein/creatinine ratio } & $R=0.087$ & $R=0.253$ \\
\hline & $P=0.593$ & $P=0.016^{*}$ \\
\hline \multirow[t]{2}{*}{ Cholesterol } & $R=-0.067$ & $R=-0.062$ \\
\hline & $P=0.565$ & $P=0.460$ \\
\hline \multirow[t]{2}{*}{ Triglyceride } & $R=-0.032$ & $R=-0.020$ \\
\hline & $P=0.783$ & $P=0.815$ \\
\hline \multirow[t]{2}{*}{ WBC } & $R=0.182$ & $R=0.068$ \\
\hline & $P=0.115$ & $P=0.421$ \\
\hline \multirow[t]{2}{*}{ Neutrophil } & $R=0.204$ & $R=0.054$ \\
\hline & $P=0.077$ & $P=0.524$ \\
\hline \multirow[t]{2}{*}{ B lymphocytes } & $R=-0.087$ & $R=-0.209$ \\
\hline & $P=0.453$ & $P=0.012^{*}$ \\
\hline \multirow[t]{2}{*}{ B1 lymphocytes } & $R=-0.039$ & $R=-0.195$ \\
\hline & $P=0.74$ & $P=0.02^{*}$ \\
\hline \multirow[t]{2}{*}{ B2 lymphocytes } & $R=-0.057$ & $R=-0.208$ \\
\hline & $P=0.628$ & $P=0.013^{*}$ \\
\hline
\end{tabular}


IMT, intima-media thickness; CKD, chronic kidney disease; SCr, serum creatinine; WBC, white blood cell.

Figures
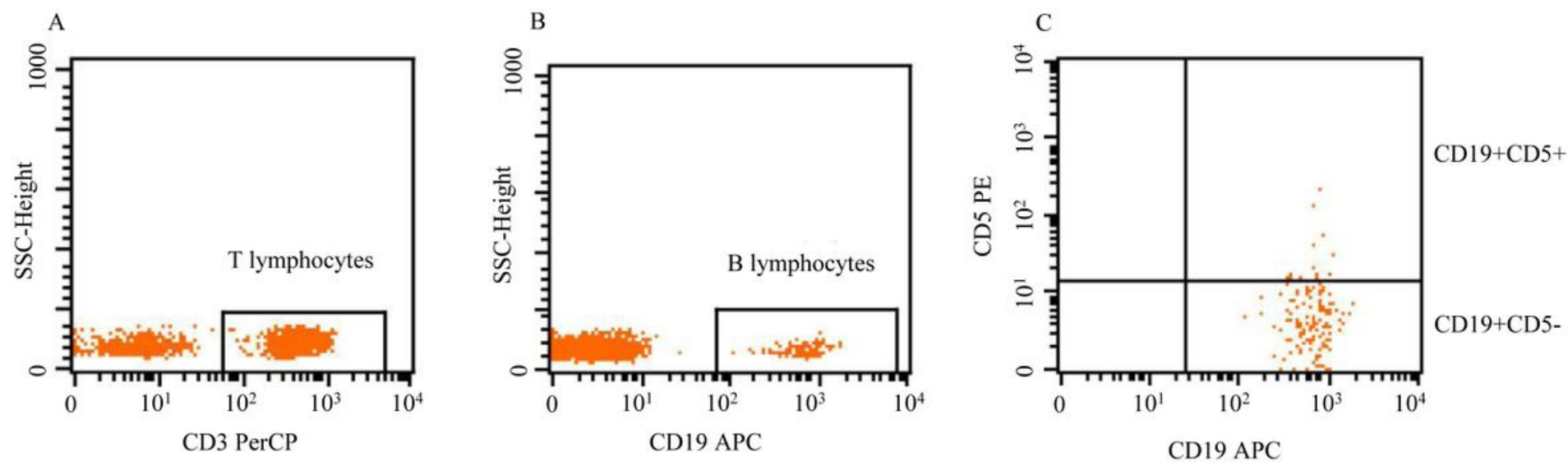

Figure 1

Flow cytometric analysis of lymphocytes, including T lymphocytes (CD3+) and B lymphocytes (CD19+). B cells were divided into B1 and B2 cells according to the surface expression of CD5+, CD19+CD5+ (innate B1 cells), and CD19+CD5- (conventional B2 cells). 

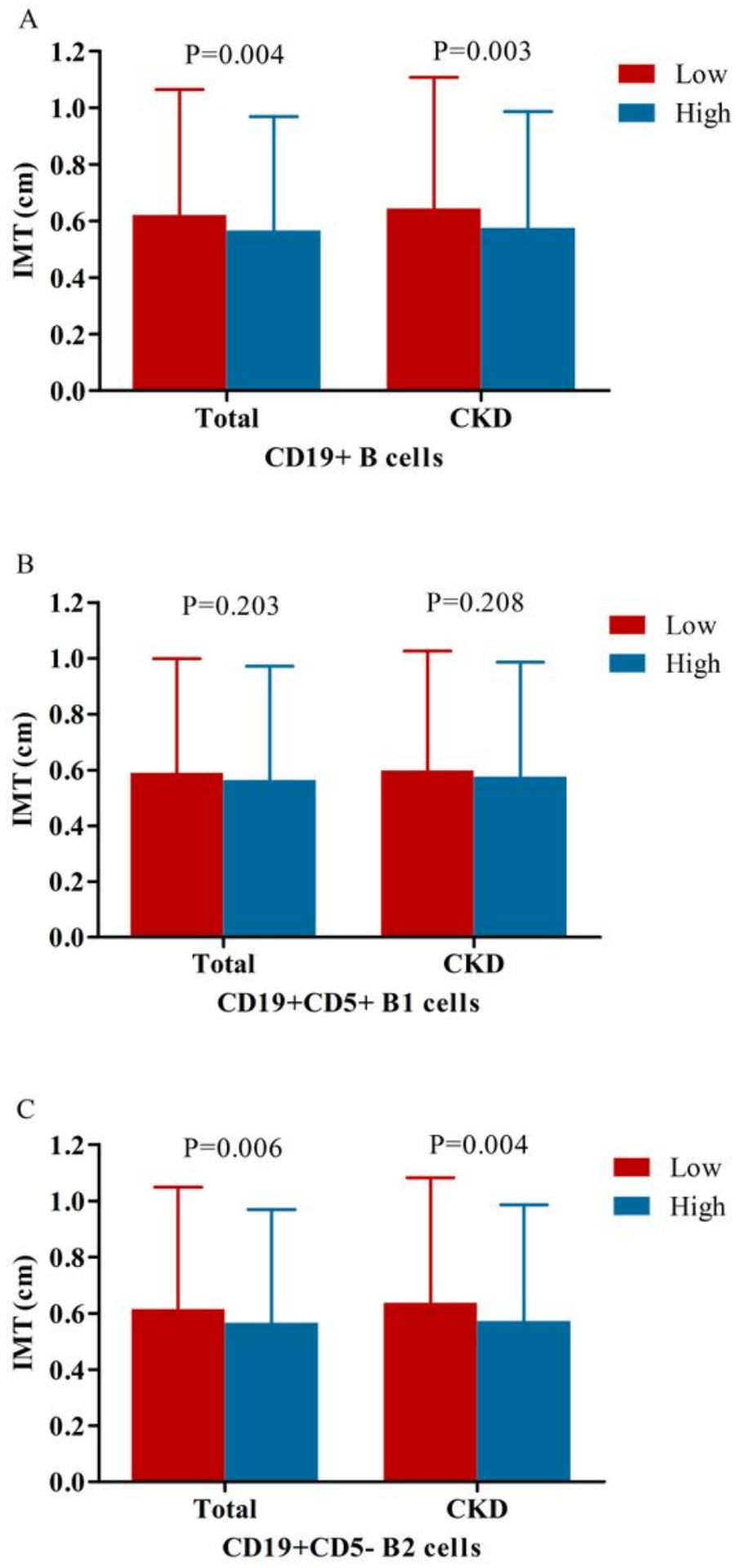

Figure 2

Comparison of intima-media thickness (IMT) between low and high level of different $B$ cells in the total cohort and CKD group. (A) B cells: low: $\leq 0.06 \times 109 / \mathrm{L}$ and high: $>0.06 \times 109 / \mathrm{L}$; (B) B1 cells: low: $\leq 0.03$ $\times 109$ /L and high: $>0.03 \times 109 / \mathrm{L}$; (C) B2 cells: low: $\leq 0.05 \times 109 / \mathrm{L}$ and high: $>0.05 \times 109 / \mathrm{L}$. 

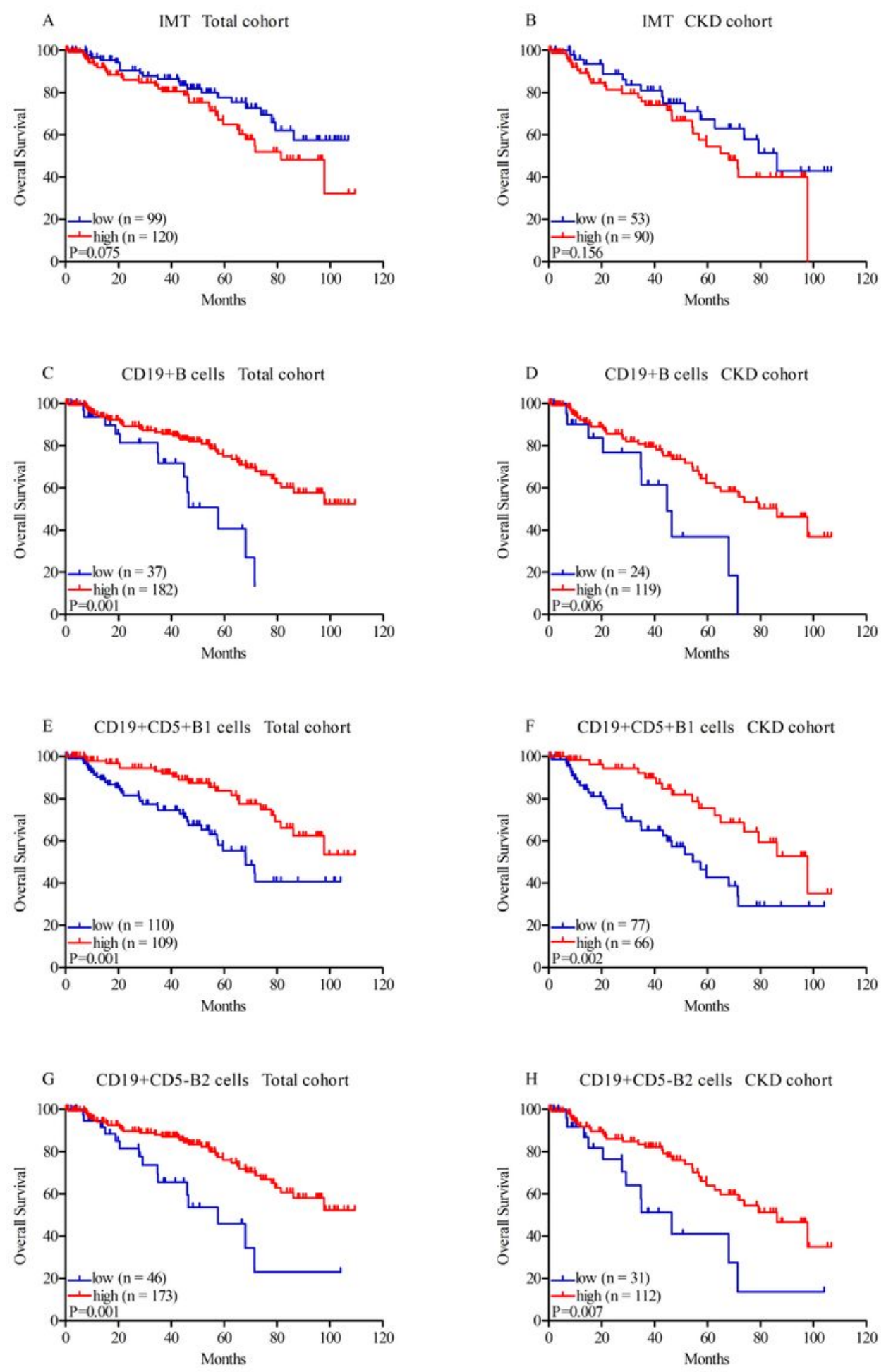

\section{Figure 3}

Kaplan-Meier survival curves of intima-media thickness (IMT), CD19+ B lymphocytes, CD19+CD5+ B1 lymphocytes, and CD19+CD5- B2 lymphocytes in the total cohort $(A, C, E, G)$ and CKD group $(B, D, F, H)$. IMT, B, B1 and B2 lymphocytes were divided into two groups (low and high) according to the optimal cutoff points, IMT: low: $\leq 1.0 \mathrm{~cm}$ and high: $>1.0 \mathrm{~cm}$; B cells: low: $\leq 0.06 \times 109 / \mathrm{L}$ and high: $>0.06 \times 109$ /L; 
B1 cells: low: $\leq 0.03 \times 109$ /L and high: $>0.03 \times 109 / \mathrm{L}$; B2 cells: low: $\leq 0.05 \times 109 / \mathrm{L}$ and high: $>0.05 \times$ 109 /L. 